Quim. Nova, Vol. 36, No. 9, 1430-1433, 2013

\title{
SIMULTANEOUS ANALYSIS OF SATURATED AND UNSATURATED FATTY ACIDS PRESENT IN PEQUI FRUITS BY CAPILLARY ELECTROPHORESIS
}

\author{
Patrícia M. de Castro Barra and Marcone A. L. de Oliveira* \\ Departamento de Química, Universidade Federal de Juiz de Fora, Cidade Universitária, 36036-330 Juiz de Fora - MG, Brasil \\ Bárbara Nery-Enes, Leandro de M. Cardoso, Cristiane do C. Cesário, Ana V. B. Moreira, Helena M. Pinheiro-Sant'Ana \\ and Maria do C. G. Peluzio \\ Departamento de Nutrição e Saúde, Universidade Federal de Viçosa, Avenida PH Rolfs, 36571-000 Viçosa - MG, Brasil
}

Recebido em 26/3/13; aceito em 29/5/13; publicado na web em 2/8/13

\begin{abstract}
In the current study, an alternative method has been proposed for simultaneous analysis of palmitic, stearic, oleic, linoleic, and linolenic acids by capillary zone electrophoresis (CZE) using indirect detection. The background electrolyte (BGE) used for the analysis of these fatty acids (FAs) consisted of $15.0 \mathrm{mmol} \mathrm{L}-1 \mathrm{NaH}_{2} \mathrm{PO}_{4} / \mathrm{Na}_{2} \mathrm{HPO}_{4}$ at $\mathrm{pH} 6.86,4.0 \mathrm{mmol} \mathrm{L}-1$ SDBS, $8.3 \mathrm{mmol} \mathrm{L}-1$ Brij 35, 45\% v/v acetonitrile (can), and 2.1\% n-octanol. The FAs quantification of FAs was performed using a response factor approach, which provided a high analytical throughput for the real sample. The CZE method, which was applied successfully for the analysis of pequi pulp, has advantages such as short analysis time, absence of lipid fraction extraction and derivatization steps, and no significant difference in the $95 \%$ confidence intervals for FA quantification results, compared to the gas chromatography official method (AOCS Ce 1h-05).
\end{abstract}

Keywords: pequi fruit; gas chromatography; capillary zone electrophoresis.

\section{INTRODUCTION}

Brazil is the most diverse country in the planet in terms of its vegetation types, and interest for its native fruits is increasing worldwide. Its large geographic area has a great variety of vegetation; several of its fruits have not yet been studied well. The Cerrado biome is an important Brazilian vegetation area, covering about $21 \%$ of the country's land territory, and harbors a great diversity of fauna and flora. ${ }^{1}$ Pequi tree is one of the typical species found in Brazilian Cerrado and its fruit, the pequi (Caryocar brasiliense Camb.), is one of the most commercialized fruits of this biome. It has many applications in food, medicine, and cosmetic industries because of its high contents of carotenoids, and oleic and palmitic fatty acids (FAs). ${ }^{2}$ Pequi pulp has a high lipid content, and the fruit also is an important source of micronutrients essential to human health, such as carotenoids, which have antioxidant and provitamin A activities. However, there is little information about its oil composition and content of vitamins, in particular vitamin E. ${ }^{3}$

Composition of the FAs present in pequi oil varies according to the region of their production, climate condition, and time of harvest. ${ }^{1}$ Regardless of this variation, oleic acid ( -9$)$ is the major component of the oil, followed by palmitic acid. ${ }^{1,3}$ Pequi oil is used as an ingredient in preparation of food; substituting other oils such as soya and dendê oils with pequi oil will account for $50.9 \%$ and $22.6 \%$ of the recommended daily amount for children and adults, respectively (considering consumption of $9 \mathrm{~g}$ of oil, as recommended by the Food Pyramid). ${ }^{4}$ Therefore, determination of FAs is important for chemical characterization of edible oils and fats and for quality control of several products.

The most common procedures used to measure FA concentration involve the following steps: first, extraction of lipids from a sample, generally based on the Folch or modified Folch method; second, isolation of FAs from the rest of the lipids by thin-layer chromatography (TLC) and/or solid-phase extraction (SPE); next, derivatization of

\footnotetext{
*e-mail: marcone.oliveira@ufjf.edu.br
}

FAs to fatty acid methyl esters (FAMEs); and finally quantification of FAMEs by gas chromatography (GC) ${ }^{5}$ Chromatographic determination of FAMEs and their separation into individual components are mostly performed using capillary $\mathrm{GC}^{5}$ and, less frequently, using high-performance liquid chromatography (HPLC). ${ }^{6}$

In the past decade, capillary electrophoresis (CE) has been used as a rapid, alternative technique for the analysis of FAs present in oils and fats because of the following advantages: easy sample preparation (no derivatization or methylation steps) and the use of nonspecific columns, simple background electrolytes (BGEs), and a small volume of reagents that can be purchased easily and are of low cost. ${ }^{7-14}$ The analysis by CE is performed in a counter-electro-osmotic mode (electrophoretic and electro-osmotic mobilities in opposite directions) using alkaline buffers (the species are analyzed as anions), where FAs with longer chains elute first and are detected by indirect UV measurement. ${ }^{10}$ However, based on the current analytical scenario, there is considerable room for improvement in FA separation by CE. In this context, a rapid and efficient method for the analysis of usual saturated and unsaturated long-chain FAs (such as stearic (C18:0), oleic (C18:1 9c), palmitic (C16:0), linoleic (C18:2cc), and linolenic (C18:3) acids) under indirect UV detection using CE, without carrying out the derivatization and lipid fraction extraction steps, has been proposed and compared with the corresponding GC official method. Figure 1 shows the structures of these FAs.

\section{EXPERIMENTAL}

\section{Chemicals and materials}

All reagents were of analytical grade and the water used was purified by deionization (Milli-Q system; Millipore, Bedford, MA, USA). The solvents purchased, including methanol $(\mathrm{MeOH})$ (Vetec, Rio de Janeiro, Brazil), acetonitrile (ACN) (Merck, Rio de Janeiro, Brazil), hexanol, petroleum ether, and 1-octanol (Merck, Rio de Janeiro, Brazil), were of chromatographic grade. Reagents such as polyoxyethylene 23 lauryl ether (Brij 35ß) and sodium dodecyl 


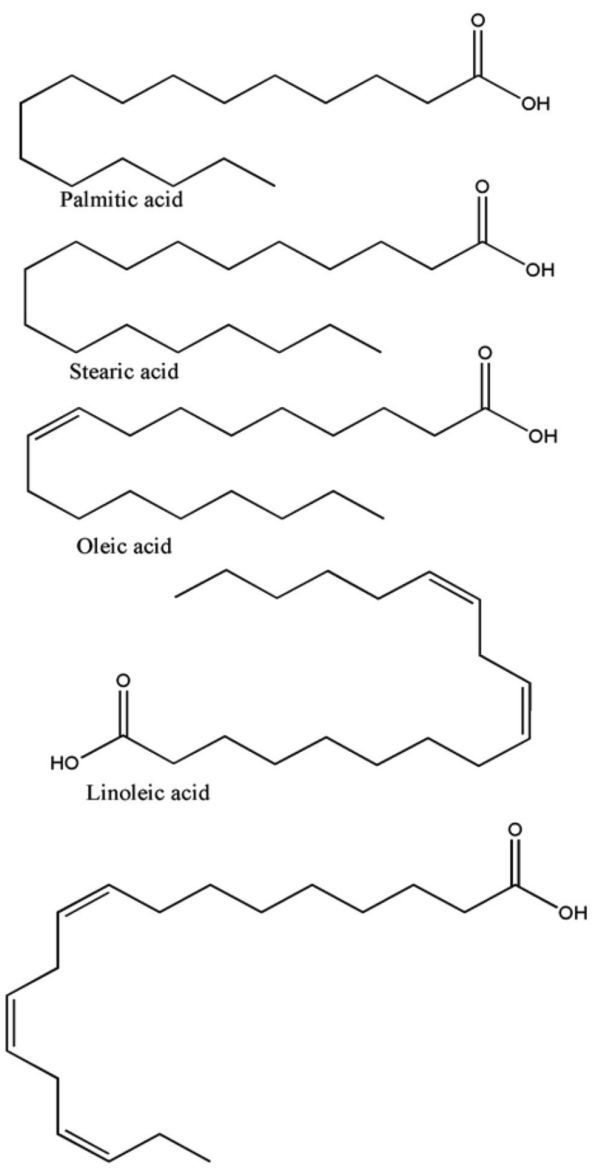

Linolenic acid

Figure 1. Chemical structures of FA analyzed in this study

benzene sulfonate (SDBS) were purchased from Sigma-Aldrich (St. Louis, MO, USA), and $\mathrm{KOH}, \mathrm{H}_{2} \mathrm{SO}_{4}, \mathrm{NaOH}, \mathrm{NH}_{4} \mathrm{Cl}$, and $\mathrm{HCl}$ from Merck (Rio de Janeiro, Brazil).

Standard FAs (C13:0, C15:0, C16:0, C18:0, C18:1 9c, C18:1 9t, C18:2cc, and C18:3ccc) were purchased from Sigma-Aldrich (St. Louis, MO, USA). Individual FA stock solutions at a concentration of $20.0 \mathrm{mmol} \mathrm{L}^{-1}$ were prepared by dissolving appropriate amounts of the above-mentioned standard FAs in $\mathrm{MeOH}$; they were stored in a freezer until analysis. A mixture of all the standard FAs was prepared at a concentration of $0.5 \mathrm{mmol} \mathrm{L}^{-1}$ by appropriate dilutions with $\mathrm{MeOH}$.

A mixture of FAME standards containing 37 FAMEs having between 4 and 24 carbon atoms (Supelco Inc., Bellefonte, PA, USA), with certificated quantities of each compound; a mixture of $c i s /$ trans FAME isomers of 18:2 (cc, ct, tc, tt) and 18:3 (ccc, cct, $c t t, t c c, t t c, t c t$, $c t c, t t t$ ) (Sigma Chemical Co, St Louis, MO, USA); individual FAME standards of about $99 \%$ purity (Sigma Chemical Co, St Louis, MO, USA): elaidic (18:1 9t), 18:1 7c, 18:1 12c, and conjugated linoleic (18:2 $9 c 11 t$ and 18:2 10t12c) acids; and an internal standard (IS) C13:0 were used for the experiment.

An aqueous Brij 35 stock solution $\left(50.0 \mathrm{mmol} \mathrm{L}^{-1}\right.$ concentration) was prepared by weighing an appropriate amount of the reagent and dissolving it in a $100.0 \mathrm{~mL}$ volumetric flask. For preparing a sodium hydroxide $(\mathrm{NaOH})$ solution of $0.5 \mathrm{~mol} \mathrm{~L}^{-1}$ concentration, corresponding amount was weighed and dissolved in a $100.0 \mathrm{~mL}$ volumetric flask and the volume was made up with $\mathrm{MeOH}$. An aqueous SDBS stock solution was prepared by weighing an amount corresponding to a concentration of $100.0 \mathrm{mmol} \mathrm{L}^{-1}$ and dissolving it in a $100.0 \mathrm{~mL}$ volumetric flask.

Aqueous buffer stock solutions at concentrations of $100.0 \mathrm{mmol}$ $\mathrm{L}^{-1}$ were prepared using appropriate amounts of monobasic sodium phosphate $\left(\mathrm{NaH}_{2} \mathrm{PO}_{4}\right)$; in addition, solutions of dibasic sodium phosphate $\left(\mathrm{Na}_{2} \mathrm{HPO}_{4}\right)$ at a concentration of $50.0 \mathrm{mmol} \mathrm{L}{ }^{-1}$ were prepared by weighing the corresponding amount and dissolving in a $250.0 \mathrm{~mL}$ volumetric flask. Phosphate buffers and the Brij 35 stock solutions were kept in a freezer to prevent mold formation. Fresh working electrolyte solutions were prepared by appropriate dilutions of stocks through incorporation of solvents.

Pequi fruits were purchased from the local market of Belo Horizonte city, Minas Gerais, Brazil.

\section{Instrumentation}

\section{CE system}

Separation optimization experiments were conducted using a CE system (HP3d CE, Agilent Technologies, Palo Alto, CA, USA) equipped with a diode-array detector (with indirect detection), a temperature control device (set at $25{ }^{\circ} \mathrm{C}$ ), and a data acquisition and treatment software (HP ChemStation, rev A.06.01). Samples were injected hydrodynamically (12.5 mbar for $5 \mathrm{~s}$ ) and the electrophoretic system was operated under normal polarity and constant voltage $(+19 \mathrm{kV})$; manual integration was performed by adjusting peaks and baselines. For all the experiments, a fused-silica capillary tube with fluoropolymer (TSH) external coating (Polymicro Technologies, Phoenix, AZ, USA) was used; the tube was $48.5 \mathrm{~cm}$ long ( $40 \mathrm{~cm}$ effective length), with an inner (id) and an outer (od) diameter of 75 and $375 \mu \mathrm{m}$, respectively.

\section{Gas chromatography}

FAMEs, prepared according to the Hartman and Lago ${ }^{15}$ procedure, were analyzed by GC on a Shimadzu gas chromatograph (GC17A model), equipped with a flame ionization detector (FID), using a fused-silica capillary column with a cyano propyl polysiloxane stationary phase (CP 7420, $100 \mathrm{~m}, 0.25 \mathrm{~mm}, 0.25 \mu \mathrm{m}$; Varian, USA). The analysis was carried out under the chromatographic conditions established by the AOCS official method Ce $1 \mathrm{~h}-05:{ }^{16}$ an isothermal column temperature of $180{ }^{\circ} \mathrm{C}$, injector and detector temperature of $250{ }^{\circ} \mathrm{C}$, use of hydrogen as the carrier gas, and column pressure of $170 \mathrm{kPa}$. The compounds were identified by comparison of their retention times with FAME 13:0 (IS). Appropriate response factors were employed to convert the area percentage of FAME into true weight percentage. FAs were determined by adding FAME 13:0 as an IS (Sigma Aldrich ${ }^{\circledR}$ ) and expressed as $g / 100 \mathrm{~g}$ of the sample. The precision of the method was evaluated by relative standard deviation (\%RSD) (two genuine replicates).

\section{Sample preparation}

\section{Capillary electrophoresis}

Approximately $200 \mathrm{mg}$ pequi fruits were ground, homogenized, and then saponified in $2.0 \mathrm{~mL}$ of methanolic $\mathrm{NaOH}$ solution $(0.5 \mathrm{~mol}$ $\left.\mathrm{L}^{-1}\right)$ in a hot water bath $\left(75-80^{\circ} \mathrm{C}\right)$ for $25 \mathrm{~min}$. Saponification contents were then diluted in a $10.0 \mathrm{~mL}$ volumetric flask. Before $\mathrm{CE}$ injection, samples were diluted in $\mathrm{MeOH}(1: 10 \mathrm{v} / \mathrm{v})$. The mass of any solid residue remaining in the saponification flask was weighed before the final calculation and was subtracted from the original mass. Analyses were performed in duplicate; the saponification scheme is shown in Figure 2.

\section{Official method by GC}

Lipid fraction of pequi fruits was extracted by the Folch method; ${ }^{17}$ next, the extracted sample was saponified in $2.0 \mathrm{~mL}$ of methanolic $\mathrm{NaOH}$ solution $\left(0.5 \mathrm{~mol} \mathrm{~L}^{-1}\right)$ at $75-80^{\circ} \mathrm{C}$ for $25 \mathrm{~min}$ in a hot aqueous bath, followed by methylation according to the method of Hartman and Lago. ${ }^{15}$ All the samples were ground and homogenized before the preparation steps, and they were analyzed in genuine duplicate. 


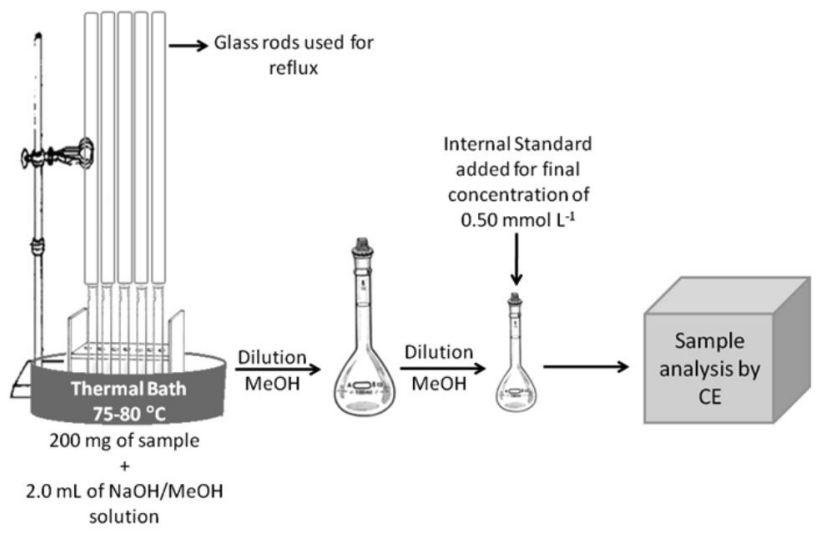

Figure 2. Preparation of pequi sample using CE method

\section{Statistical analysis}

The analyses were performed in duplicate. Data were expressed as mean \pm standard deviation. For comparison among means obtained by different methods, normality test was performed and the paired $t$ test was conducted; no significant difference was observed in the 95\% confidence levels ( $\mathrm{p}>0.05$ ) between GC and CE methods. Pearson correlation was used to test the correlation between GC and $\mathrm{CE}$ methods used for the characterization of lipid profile. ${ }^{18}$

\section{Analytical procedures}

Prior to use, new capillaries were conditioned by pressure flushing with $1.0 \mathrm{~mol} \mathrm{~L}^{-1} \mathrm{NaOH}$ (30 min), deionized water (5 min), and electrolyte solution (10 min). In between runs, capillaries were regenerated by washing with $0.2 \mathrm{~mol} \mathrm{~L}^{-1} \mathrm{NaOH}$ ( 2 min), deionized water ( $2 \mathrm{~min}$ ), and fresh electrolyte solution ( $3 \mathrm{~min}$, pressure flush). This conditioning procedure was found to be critical for ensuring peak area and migration time repeatability, and for preventing the deleterious effect of solute adsorption onto the capillary wall.

\section{RESULTS AND DISCUSSION}

The use of a BGE for FA analysis of pequi pulp was according to the method described in a previously published paper. ${ }^{19}$ Consequently, the BGE consisted of $15.0 \mathrm{mmol} \mathrm{L}-1 \mathrm{NaH}_{2} \mathrm{PO}_{4} / \mathrm{Na}_{2} \mathrm{HPO}_{4}$ at $\mathrm{pH} 6.86$, $4.0 \mathrm{mmol} \mathrm{L}^{-1}$ SDBS, $8.3 \mathrm{mmol} \mathrm{L}^{-1}$ Brij $35,45 \% \mathrm{v} / \mathrm{v}$ can, and $2.1 \%$ n-octanol.

On the other hand, FA quantification of the real sample was based on a statistical study that involved response factor $\left(\mathrm{R}_{\mathrm{fi}}\right)$ calculation using $\mathrm{C} 13: 0$ as an IS. To calculate $\mathrm{R}_{\mathrm{f}}$, a random experiment was performed in genuine replicates using C18:0, C18:1 9t, C18:1 9c, C16:0, $\mathrm{C} 18: 2 \mathrm{cc}$, and $\mathrm{C} 18: 3 \mathrm{ccc}$ standard solutions at varying concentrations of $0.15,0.30,0.50,0.70,0.90$, and $1.10 \mathrm{mmol} \mathrm{L}^{-1}$, and $\mathrm{C} 13: 0$ at a fixed concentration of $0.5 \mathrm{mmol} \mathrm{L}^{-1} .^{19}$

The $R_{\text {fi }}$ was calculated just once for each standard FA in the preliminary experiment (under controlled operational conditions), taking into account a rigorous statistical evaluation of the regression models by performing normality, homoscedasticity, and independence tests in residues and evaluation through the lack of fit test (ANOVA) in data set. If these tests did not present significant evidence for the considered interval (in the present case, all values obtained in the statistical tests were considered to be within the $95 \%$ confidence interval), the slopes obtained could be used as the response factors for sample quantification. On the other hand, if the analysis had been performed using the same concentration of IS and same operational conditions (capillary dimensions, wavelength, cartridge temperature, etc.) as in the preliminary experiment, and there had been no violation of assumptions in the statistical tests (normality, homoscedasticity, independence, and lack of fit), response factors would be calculated for each FA, instead of performing experiments to obtain their values.

The $\mathrm{R}_{\mathrm{fi}}$ values calculated for quantification were $0.477,0.555$, $0.589,0.626$, and 0.818 for C18:0, C18:1c, C16:0, C18:2cc, and C18:3ccc, respectively. ${ }^{19}$ These $\mathrm{R}_{\mathrm{fi}}$ values were calculated using the following mathematical expression:

$$
\frac{A_{F A_{i}}}{\left[F A_{i}\right]}=R_{f_{i}} \frac{A_{C 13: 0}}{[C 13: 0]}
$$

where $\mathrm{A}_{\mathrm{FAi}}$ is the FA area, $\mathrm{A}_{\mathrm{Cl3}: 0}$ is the IS area, $\left[\mathrm{FA}_{\mathrm{i}}\right]$ is the FA concentration in mmol $\mathrm{L}^{-1}$, and [C13:0] is the IS concentration fixed at $0.5 \mathrm{mmol} \mathrm{L}^{-1}$. Subscript $i$ represents the different FAs: C18:0, C18:1 9c, C16:0, C18:2cc, and C18:3ccc.

Since the regression model diagnosis was considered satisfactory, the slope could be used as $R_{f}$ in equation (1), as long as the C13:0 was used at a concentration of $0.5 \mathrm{mmol} \mathrm{L} \mathrm{L}^{-1}$, while concentrations of other FAs remaining unknown. Percentage for each FA $\left(\% \mathrm{FA}_{\mathrm{i}}\right)$ in the samples was calculated using equation (2), obtained after rearranging equation (1):

$$
\% F A_{i}=\frac{A_{F A_{i}}[C 13: 0] \cdot V \cdot M W_{F A_{i}}}{R_{f_{i}} \cdot A_{C 13: 0} \cdot m}
$$

where $\mathrm{A}_{\mathrm{FA}}$ is the area of each FA, $\mathrm{A}_{\mathrm{C} 13: 0}$ is IS area, \%FA is the percentage of each FA, [C13:0] is the IS concentration that is fixed at $0.5 \mathrm{mmol} \mathrm{L}^{-1}, \mathrm{~V}$ is the volume in liters, $\mathrm{m}$ is the sample mass in milligrams, $\mathrm{R}_{\mathrm{f}}$ is the response factor (fitted model slope), and $\mathrm{MW}_{\mathrm{FA}}$ is the molecular weight of each FA.

Figure 3 shows the electropherograms obtained from the analysis of the standards and pequi samples. The BGE contained $15.0 \mathrm{mmol}$ $\mathrm{L}^{-1} \mathrm{NaH}_{2} \mathrm{PO}_{4} / \mathrm{Na}_{2} \mathrm{HPO}_{4}$ at $\mathrm{pH}$ 6.86, $4.0 \mathrm{mmol} \mathrm{L}{ }^{-1} \mathrm{SDBS}, 8.3 \mathrm{mmol}$ $\mathrm{L}^{-1} \mathrm{Brij} 35,45 \% \mathrm{v} / \mathrm{v}$ can, and $2.1 \% \mathrm{n}$-octanol. It is noteworthy that indirect UV detection was applied for FA analysis and peak integration was observed at a wavelength of $224 \mathrm{~nm}$.
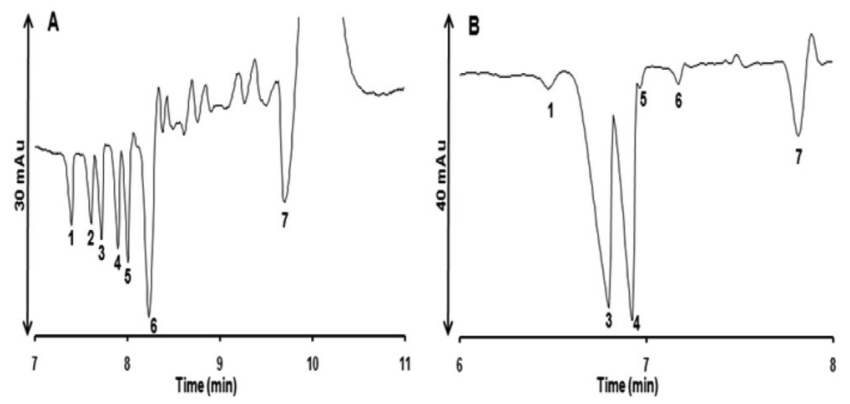

Figure 3. (A) Standard FA electropherograms of (1) C18:0, (2) C18:1 9t, (3) C18:1 9c, (4) C16:0, (5) C18:2, (6) C18:3, and (7) C13:0 (IS), all at a concentration of $0.50 \mathrm{mmol} \mathrm{L}^{-1}$. (B) Pequi sample electropherogram. Operational conditions: injection for $4 \mathrm{~s}$ at $12.5 \mathrm{mbar},+19 \mathrm{kV}$ applied voltage, and $25^{\circ} \mathrm{C}$ cartridge temperature, and indirect detection at $224 \mathrm{~nm}$. Electrolyte: 15.0 mmol L ${ }^{-1} \mathrm{NaH}_{2} \mathrm{PO}_{4} / \mathrm{Na}_{2} \mathrm{HPO}_{4}$ at $\mathrm{pH}$ 6.86, $4.0 \mathrm{mmol} \mathrm{L}^{-1} \mathrm{SDBS}, 8.3 \mathrm{mmol} \mathrm{L} \mathrm{L}^{-1}$ Brij 35, $45 \% v / v$ can, and $2.1 \%$ n-octanol

\section{Comparison between $\mathrm{CE}$ and GC methods}

To check the reliability of the CE method used for FA analysis, the pequi fruit samples were analyzed in genuine duplicate and the 
results were compared with the AOCS official GC method Ce 1h-05. ${ }^{16}$ Table 1 shows the statistical results obtained during genuine duplicate analyses, expressed in mean values (Shapiro-Wilk normality test and paired sample $t$ test) for CE and GC. For normality test, no significant difference was found for the $95 \%$ confidence interval because $\mathrm{p}$-values were found to be higher than $0.05(\mathrm{p}=0.905)$. According to the paired sample $t$ test, no significant difference was observed in the $95 \%$ confidence interval $(\mathrm{p}=0.989)$ between the two methodologies, and Pearson correlation coefficient was equal to 0.956 .

Table 1. Fatty acids analysis statistical results for $\mathrm{CE}$ and GC methods

\begin{tabular}{ccc}
\hline FA & \% FA by CE & \% FA by GC \\
\hline C16:0 & 39.07 & 35.56 \\
& 38.32 & 35.10 \\
mean & $\mathbf{3 8 . 7 0}$ & $\mathbf{3 5 . 3 3}$ \\
sd & $\mathbf{0 . 5 2}$ & $\mathbf{0 . 3 2}$ \\
C18:0 & 2.68 & 2.00 \\
& 2.51 & 1.94 \\
mean & $\mathbf{2 . 6 8}$ & $\mathbf{1 . 9 7}$ \\
sd & $\mathbf{0 . 2 3}$ & $\mathbf{0 . 0 4}$ \\
C18:1 c & 55.65 & 59.90 \\
& 56.77 & 58.06 \\
mean & $\mathbf{5 6 . 2 1}$ & $\mathbf{5 8 . 9 8}$ \\
sd & $\mathbf{0 . 7 9}$ & $\mathbf{1 . 3 0}$ \\
C18:2 cc & 1.27 & 1.17 \\
& 0.99 & 3.55 \\
mean & $\mathbf{1 . 1 3}$ & $\mathbf{2 . 3 6}$ \\
sd & $\mathbf{0 . 1 9}$ & $\mathbf{1 . 6 8}$ \\
C18:3 ccc & 1.14 & 1.94 \\
& 1.12 & 1.90 \\
mean & $\mathbf{1 . 1 3}$ & $\mathbf{1 . 9 2}$ \\
sd & $\mathbf{0 . 0 1}$ & $\mathbf{0 . 0 3}$
\end{tabular}

Normality test: $\mathrm{p}$-value; 0.905; Paired test: $\mathrm{p}$-value: 0.372; Pearson correlation: 0.996

The results are satisfactory, indicating that the CE method can be used successfully for the determination of FA levels in this sample, without carrying out the steps of derivatization and lipid fraction extraction used in the classical method.

A scheme comparing the attractive CE method and the AOCS official GC method Ce 1h-05, in terms of analysis time, amount of chemical reagents necessary, and analytical throughput, is shown in Figure 4.

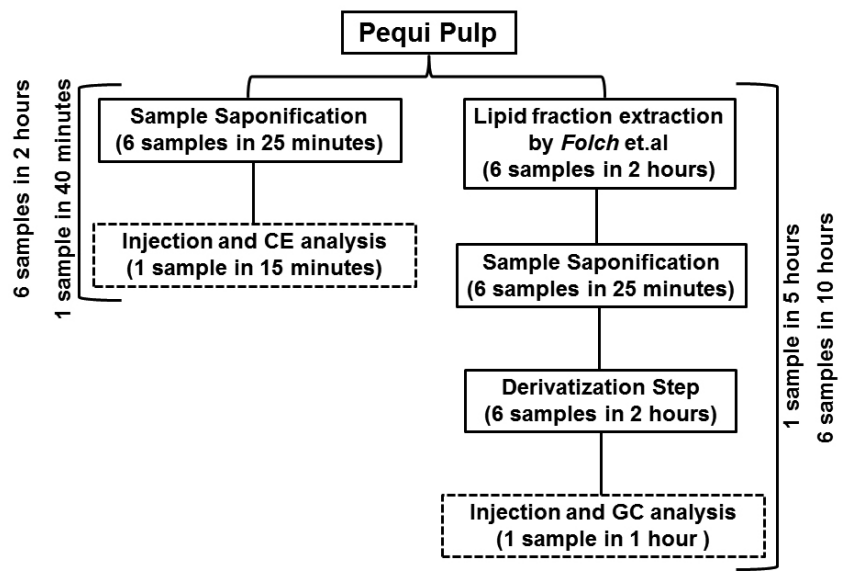

Figure 4. Analytical throughput comparison of CE and GC methods used for the analysis of pequi pulp

\section{CONCLUSION}

Pequi fruits have a high content of unsaturated FAs, with oleic acid being the major component, followed by palmitic acid. No statistical difference was observed in the $95 \%$ confidence intervals between capillary zone electrophoresis (CZE) and GC official method for FA analysis. Besides, the optimized CE method presents certain advantages, including short running time, response factor approach for FA quantification, simple steps for sample preparation (that is, absence of methylation reaction), reduction in costs with the use of organic reagents, and short total analysis time (higher throughput), in comparison with the classical GC official method. The CZE method reported in the present work is simple, easy, "ecofriendly," and fit as an attractive method for application in screening or quality control of food products.

\section{ACKNOWLEDGMENTS}

The authors wish to thank the Conselho Nacional de Desenvolvimento Científico e Tecnológico (CNPq - 475055/20110 and 301689/2011-3), Fundação de Amparo à Pesquisa do Estado de Minas Gerais of Brazil (FAPEMIG-CEX APQ 02420-11 and CEXPPM 00205-11), and Coordenação de Aperfeiçoamento de Pessoal de Nível Superior (CAPES) for fellowships and financial support.

\section{REFERENCES}

1. Oliveira, M. N. S. D.; Gusmão, E.; Lopes, P. S. N.; Simões, M. O. M.; Ribeiro, L. M.; Dias, B. A. S.; Revista Brasileira de Fruticultura 2006, 28,380 .

2. Silva, E. C.; Soares, I. C.; Helou, J. H.; Cosmet. Toiletries 1993, 5, 31.

3. Lima, A. D.; Silva, A. M. D. O. E.; Trindade, R. A.; Torres, R. P.; Mancini-Filho, J.; Revista Brasileira de Fruticultura 2007, 29, 695.

4. IOM. Dietary reference intakes. Proposed definition of dietary fiber, National Academies Press, 2001.

5. Delmonte, P.; Rader, J. I.; Anal. Bioanal. Chem. 2007, 389, 77.

6. Delmonte, P.; Yurawecz, M. P.; Mossoba, M. M.; Cruz-Hernandez, C.; Kramer, J. K. G.; J. AOAC Int. 2004, 87, 563.

7. Oliveira, M. A. L.; Solis, V. S.; Gioelli, L. A.; Polakiewicz, B.; Tavares, M. F. M.; Electrophoresis 2003, 24, 1641.

8. Otieno, A. C.; Mwongela, S. M.; Anal. Chim. Acta 2008, 624, 163.

9. Barra, P. M. C.; Barra, M. M.; Azevedo, M. S.; Fett, R.; Micke, G. A.; Costa, A. C. O.; Oliveira, M. A. L.; Food Control 2012, 23, 456.

10. Castro, P. M.; Barra, M. M.; Ribeiro, M. C. C.; Aued-Pimentel, S.; Silva, S. A.; Oliveira, M. A. L.; J. Agric. Food Chem. 2010, 58, 1403.

11. Oliveira, M. A. L.; Lago, C. L. ; Tavares, M. F. M.; Silva J. A. F. Quim. Nova 2003, 26, 821.

12. Balesteros, M.R.; Faria, A.F.; Oliveira, M.A.L. ; J. Braz. Chem. Soc. 2007, 18, 554.

13. Porto, B.S.L.; Souza, M.V.N.; Oliveira, M.A.L.; Anal. Sci. 2011, 27, 541.

14. Castro, R.J.C.; Sobrinho, F.S.; Gama, M.A.S.; Barra, P.M.C.; Antoniassi, R.; Oliveira, M.A.L.; Cent. Eur. J. Chem. 2013, 11, 286.

15. Hartman, L.; Lago, R. A. C.; Laboratory Practice 1973, 22, 475.

16. AOCS, Official Methods And Recommended Practices of the AOCS. Additions and revisions 1999-2006. Method Ce 1h-05, Champaign (IL) 2006.

17. Folch, J.; Lees, M.; Sloane-Stanley, G. H.; J. Biol. Chem. 1957, 226, 497.

18. Massart, D. L.; Vandeginste, B. G. M.; Buydens, L. M. C.; De Jong, S.; Lewi, P. J.; Smeyers-Verbeke, J; Handbook of chemometrics and qualimetrics: part A, Elsevier: New York, 1997.

19. Barra, P. M. C.; Castro, R. J. C.; Oliveira, P. L.; Aued-Pimentel, S.; Silva, S. A.; Oliveira, M. A. L.; Food Res. Int. 2013, 52, 33. 